\title{
Species composition, prevalence and seasonal variations of ixodid cattle ticks in and around Haramaya town, Ethiopia
}

\author{
Mohamed Bedasso, Belay Abebe* and Hailu Degefu \\ School of Veterinary Medicine, College of Agriculture and Veterinary Medicine, Jimma University, Ethiopia.
}

Received 17 January, 2014; Accepted 20 March, 2014

\begin{abstract}
A cross-sectional study was conducted from September 2009 to March 2010 in and around Haramaya town to determine the species composition, prevalence and seasonal variation of ixodid cattle ticks. During the study period, a total of 3117 adult ixodid cattle ticks were collected from the half body regions of 346 local breeds of cattle which were under extensive management system during early dry and early wet periods and then identified to genera and species level. Six tick species of four genera were identified in which two species each belongs to the genus Amblyomma and Rhipicephalus and one species each belong to the genus Hyalomma and Boophilus. Of the total tick collected, Amblyomma, Boophilus, Rhipicephalus and Hyalomma constitutes (65, 26.3, 10.9 and 7.8\%), respectively. The prevalence of tick species were Amblyomma varigatum (41\%) Boophilus decoloratus (26.3\%), Amblyomma coherence (14.9\%), Hyalomma rufipes (7.8\%) and Rhipicephalus evertsi (5.5\%) and Rhipicephalus pulchellus (5.4\%). The present study reveals that $A$. varigatum was the most abundant cattle tick species in and around Haramaya town and while the $R$. pulchelusis the least abundant. There was no statistical significance difference $(P>0.05)$ in tick infestation between sex of cattle's but tick infestation was significantly $(P<0.05)$ higher in adult age groups of cattle compared to caves. The favorable predilection sites of Amblyomma species were ano-vulva, udder/scrotum, but $B$. decoloratus preferred dewlap, perineum and udder/scrotum. The sex ratio of all tick species identified during this study period was skewed towards male except for $B$. decoloratus. The present study on tick species composition and seasonal variability contributes its part on how to design control strategies for ticks and tick borne diseases in the study area.
\end{abstract}

Key words: Ixodid cattle tick, seasonal variation, tick species composition, prevalence, Haramaya.

\section{INTRODUCTION}

In Ethiopia, agriculture is the dominant sector of the economy and accounts for over $50 \%$ of the gross domestic product (GDP), 35\% of the export revenue, and provides livelihood for over $80 \%$ of its inhabitants. At present, four-fifths of the Ethiopian population is engaged in agriculture as small holder farmers who are responsible for $95 \%$ of the total agricultural output livestock provides about 35\% of agricultural products (Mengistu, 1997).

Ethiopia is one of the countries with the largest number 
of livestock in Africa and livestock production plays a major role in the overall development of Ethiopian's agriculture. Nevertheless, cattle productivity is low (Alekaw, 2000). Factors contributing for this may include the improper management, diseases, nutritional deficiencies, harsh environment and genetic factors.

In Ethiopia, approximately 44.3 million cattle, 46.9 million small ruminants and more than one million camels contributes to the economic welfare of the people by providing hide, power, and traction for agricultural purpose and fertilizer for increasing the productivity of smallholding (Minjauw and Mcleod, 2003).

Ixodid ticks are one of the most common and harmful blood sucking ectoparasite of cattle worldwide. They are responsible for a wide range of livestock health problems in several countries of the world. They reduce cattle productivity, milk yield and skin and hide quality and increase susceptibility to other disease (Tsegaye et al., 2013). Approximately, $80 \%$ of cattle populations of the world are at risk of tick infestation and tick born diseases. In addition to sucking large volume of blood, ticks inject pathogens such as viruses, bacteria, protozoa and toxins into their hosts (FAO, 2004).

In Ethiopia, among the major parasitic disease, ticks and tick-born disease rank third after trypanosomiasis and endoparasitism in causing economic losses. Bekele (2002) estimated an overall loss of US\$500,000 from hide and skin down grading as a result of ticks, and approximately $65.5 \%$ of major defects of hides in Eastern Ethiopia are caused by ticks. De Castro (1997) estimated that the annual global cost associated with tick and tickborn diseases in cattle range between US\$ 13.9 and US\$18.7 billion.

In Ethiopia, ticks are common in all agro ecological zones of the country (Morel, 1980; Pegram et al., 1981). Therefore, relevant data on the population dynamics of ticks is essential for the development of effective tick and tick born disease control program.

Therefore, the current study was undertaken to assess the species composition, distribution and seasonal variation of ixodid ticks in and around Haramaya town.

\section{MATERIALS AND METHODS}

\section{Study area description}

Haramaya district is situated in Eastern Harerge zone, located in Oromia regional state of Ethiopia. The district has $521.64 \mathrm{~km}^{2}$ or $52164 \mathrm{ha}$, and it is situated at longitude of $41^{\circ} \mathrm{E}$ to $50^{\circ} \mathrm{E}$ and latitude $9^{\circ} \mathrm{N}$ to $32^{\circ} \mathrm{N}$. The altitude ranges from 1600 up to 2100 m.a.s.I. The mean annual temperature and relative humidity are $18^{\circ} \mathrm{C}$ and $65 \%$, respectively.

The area receives an annual rain fall of $800 \mathrm{~mm}$ with a bimodal distribution pattern. There are four seasons: a short rainy season (from mid-March to mid-May), a long wet season from beginning of July to end of October), a long dry season (from late October to beginning of March), and a short dry season (from end of May to end of June).

Haramaya district is grouped into arid and semi-arid climatic zone where $66.66 \%$ is Weina Dega and $33.33 \%$ is Kola. The vegetation type that constitutes the available pasture lands in this areas predominantly native grasses and legumes interspersed with open acacia a shrub land (HDARDO, 2002).

\section{Study population}

According to the Haramaya Wereda Rural Development and Agricultural Bureau, Wereda has 63,723 cattle, 13,612 sheep, 20,350 goats, 15,978 donkeys, 536 camels and 42,035 poultry. During the study period (September 2009 to March 2010) adult ixodid ticks were collected from 346 cattle consisting of 156 male and 190 female animals. All the animals were local breeds which are owned by different producers. The animals were managed under extensive production system.

\section{Study design}

\section{Cross-sectional study}

Cross-sectional study was conducted for species composition, seasonal variation and infestation of ticks. Using random sampling, 173 cattle were selected for each season and subjected to standard tick collection and identification techniques. During the study period ticks were collected from different body parts of cattle such as head, brisket, belly, dewlap, back, udder or scrotum leg, ano-genital and tail.

\section{Sampling and sample size determination method}

The sample size was calculated according to Thrusfield (1995) by taking $87.1 \%$ of expected prevalence and $5 \%$ accepted error at 95\% confidence interval.

The general formula is:

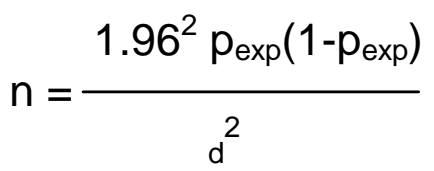

where $\mathrm{n}=$ required sample size, $p_{\exp }=$ expected prevalence, $\mathrm{d}=$ desired absolute precision.

Accordingly, the estimated sample size was 173 for early dry season and 173 for early wet season. A total of 346 cattle were sampled during the study period (from September 2009 up to March 2010).

\section{Study methodology}

\section{Tick collection technique}

Removal of feeding ticks from the animals was carried out for about seven months (November 2009 to March 2010). During sampling, each animal was either restricted in a crash, casted or laid down, and then tick collection was done. All visible attached adults' ticks were collected from different predilection sites (anal ano-vulval scrotum, udder, dewlap, chest, belly, flanks tail, back) of each animal. Adult ticks are collected from half body region of cattle at clinic; field of grazing, vaccine place, and watering place during early dry period and early wet period into the universal bottle that containing $70 \%$ of ethanol. Ticks were collected from the left body of cattle for collection using good quality forceps and using two fingers. 
Table 1. Tick species identified and their percentage of distribution during early dry and early wet periods.

\begin{tabular}{lcccccc}
\hline \multirow{2}{*}{ Tick species } & \multicolumn{2}{c}{ Season } & \multicolumn{2}{c}{ Sex } & \multirow{2}{*}{ Total } & \multirow{2}{*}{ Distribution (\%) } \\
\cline { 2 - 5 } & Dry & Wet & Male & Female & & 1252 \\
Amblyomma varigatum & 235 & 1017 & 785 & 467 & 40.1 \\
Boophilus decoloratus & 163 & 657 & 212 & 445 & 820 & 26.3 \\
Amblyomma coherence & 148 & 315 & 301 & 162 & 463 & 14.9 \\
Hyalomma rufipes & 79 & 163 & 157 & 85 & 242 & 7.8 \\
Rhipicephalus evertsi & 60 & 112 & 115 & 57 & 172 & 5.5 \\
Rhipicephalus pulchulles & 74 & 94 & 98 & 70 & 168 & 5.4 \\
Total & 759 & 2,358 & 1,831 & 1,286 & 3,117 & 100 \\
\hline
\end{tabular}

Table 2. Sex ratio of adult tick species of each period and the overall ratio of the early dry and wet periods (male:female).

\begin{tabular}{lccc}
\hline \multirow{2}{*}{ Tick species } & \multicolumn{2}{c}{ Season } & \multirow{2}{*}{ Overall } \\
\cline { 2 - 3 } & Dry & Wet & \\
\hline Amblyomma varigatum & $1: 1.94$ & $1.6: 1$ & $1: 0.8$ \\
Boophilus decoloratus & $0.4: 1$ & $0.5: 1$ & $0.45: 1$ \\
Amblyomma coherence & $1.9: 1$ & $1.8: 1$ & $1.8: 1$ \\
Hyalomma rufipes & $2.6: 1$ & $1.6: 1$ & $2.1: 1$ \\
Rhipicephalus evertsi & $1.8: 1$ & $2: 1$ & $1.9: 1$ \\
Rhipicephalus pulchulles & $1.5: 1$ & $1.3: 1$ & $1.4: 1$ \\
\hline
\end{tabular}

\section{Tick identification}

Ticks were counted, identified and recorded by species, sex and instars. All ticks counted were kept in pre-labeled universal bottles containing $70 \%$ of ethanol until identification was done according to Walker et al. (2003) and Keiser (1987). Then identification of cattle tick species was made using petri-dishes, stereomicroscope by their morphological characteristics.

\section{Data management and analysis}

Samples were labeled on the basis of species, age, sex, breed and origin of the sampled animals and then transported to Veterinary Parasitology Laboratory (Haramaya University College of Veterinary Medicine). SPSS 16.0 computer software programme was used to analyze the data.

\section{RESULTS}

\section{Tick species identified}

During the study period, a total of 3117 adult ixodid ticks were collected from a half body regions of 346 cattle that were sampled from in and around Haramaya town during the early dry and early wet season. From the collected ticks were 1831 males and 1286 females (Table 1). As a whole in the study areas four adult ixodid tick genera and six species were identified in early dry period, and similar number of genera and species of adult ixodid ticks were identified during early wet season except variation in number. During the two seasons, the genera of ticks identified were Amblyomma (65\%), Boophilus (26.3\%), Rhipicephalus (10.9\%) and Hyalomma (7.8\%), whereas the percentage of species identified was Amblyomma varigatum (41.1\%), Boophilus decoloratus (26.3\%), Amblyomma coherence (14.9\%), Hyalomma rufipes (7.8\%), Rhipicephalus evertsi (5.5\%) and Rhipicephalus pulchulles (5.4\%) (Table 1).

\section{Sex ratio of ticks}

During the study period in the study area, the numbers of male ticks were higher than the number of females in Amblyoma, Hyalomma and Rhipicephalus genera of ticks, but in case of Boophilus the numbers of females were higher than the number of males (Table 2).

\section{Attachment sites of ticks on cattle}

During the study, each species of ticks were collected from various body regions of cattle. But attachment site preference was stronger in some species than the others. The observed proportion of attachment sites for each species of the ticks during this study was summarized as depicted in Table 3. 
Table 3. Favorable attachment sites of tick species.

\begin{tabular}{ll}
\hline Species of tick & Site of attachment \\
\hline Amblyomma species & Brisket, udder and scrotum, dewlap \\
Boophilus decoloratus & Dewlap, belly/back \\
Hyalomma rufipes & Scrotum/Udder, brisket \\
Rhipicephalus species & Tail, anogenital and head/ear \\
\hline
\end{tabular}

Table 4. Infestation status of ticks on sex of cattle.

\begin{tabular}{lccccccc}
\hline Sex & $\begin{array}{c}\text { Animals } \\
\text { examined }\end{array}$ & No. positive & OR & P-value & $\begin{array}{c}\text { Lower } \\
\mathbf{9 5 \%} \mathbf{~ C l}\end{array}$ & $\begin{array}{c}\text { Prevalence } \\
(\mathbf{\%})\end{array}$ & $\begin{array}{c}\text { Upper } \\
\mathbf{9 5 \%} \mathbf{~ C l}\end{array}$ \\
\hline Male & 156 & 135 & 2.5 & 0.001 & 1.42 & 86.5 & 4.35 \\
Female & 190 & 158 & Ref* $^{*}$ & & & 83.2 & \\
Total & 346 & 293 & & 0.000 & 0.804 & 84.7 & 0.883 \\
\hline
\end{tabular}

OR: Odds ratio; Ref*: reference; $\mathrm{Cl}$ : confidence interval.

\section{Infestation status of ticks on sex of cattle}

Using univariate logistic regression to determine the infestation of ticks on the sex of cattle, the result revealed that there is no statistical significance difference between the sex of animals involved in the study and the infestation status is summarized as depicted in Table 4.

\section{Infestation status of ticks on age}

Using age as a predictor variable on infestation status of ticks in cattle, the present study revealed that animals with an age group of greater than four (>4years) has high tick infestation status (Odds ratio of 0.96 ) compared with animals with 2 to 4 years of age. In other words as the age of cattle increased, tick infestation is also increased (Table 5).

\section{Infestation status of ticks on season}

Different peaks of prevalence were recorded during the early dry period $(78.0 \%)$ and $91.3 \%$ during the early wet period. Result of the study indicated that high infestation rate was recorded during wet period than dry period in the study area. Results of the present study indicated that cattle are highly infested with ticks in wet period than dry period as depicted in Table 6 .

\section{DISCUSSION}

In and around Haramaya town all collected ticks were identified and categorized into four genera, namely, Amblyomma, Boophilus, Hyalomma, and Rhipicephalus, and also six species of these genera were recorded.
During both periods (early dry and early wet) similar genera and species were recorded in the study area. The reason of finding similar tick species during both periods was due to short period of study. The species of ticks identified were $A$. varigatum, $B$. decoloratus, $A$. coherence, $H$. rufipes, $R$. evertsi and $R$. pulchellus by decreasing order, respectively.

In this study, a total of 3117 adult ticks were collected from half-body regions of cattle in and around Haramaya town. The study indicated that the proportion and frequency of occurrence varied significantly over the season. In the study period, $H$. rufipes, $R$. eversti and $R$. pulchellus are recorded only in very small numbers, respectively.

Among the total collection, $A$. varigatum were found to be the most abundant species of all ticks in the area $(40.1 \%)$. This finding is in agreement with the previous work of Solomon et al. (1998) at Sebeta and Abernosa, respectively who recorded the highest counts of $A$. varigatum in July and April during the rainy month of the area. The adults of $A$. varigatum are usually found on their host during the rainy season (Keiser, 1988; Husen, 2009). The reason why this tick species found in a very high number was probably due to the geographic location of the area and also due to its being relatively active throughout the year. Likewise, several researches, which had been conducted in different parts of Ethiopia, indicated that $A$. varigatum is the most abundant tick species with the highest prevalence. Similar to the present study, Mesele (1989) found higher prevalence of 59 and $75.91 \%$ in and around Bahirdar, respectively.

A. variegatum is the most widely distributed cattle tick in Ethiopia (Morel, 1980; Pegram et al., 1981) and has a great economic importance, because it is an efficient vector of Cowderia ruminantum. This parasite also causes the greatest damage to the hide and skin, because of its long mouth parts which render the commodity value less 
Table 5. Infestation status of ticks based on age group of cattle.

\begin{tabular}{lcccccc}
\hline Age & Animal examined & Number positive & Odds ratio & $\mathbf{9 5 \% ~ C l}$ & P-value & Prevalence (\%) \\
\hline$<2$ years & 79 & 57 & 0.48 & $0.23-1.01$ & 0.056 & 72.2 \\
2-4 years & 94 & 79 & Ref* $^{*}$ & & & 84.2 \\
$>4$ years & 173 & 143 & 0.96 & $0.48-1.91$ & 0.91 & 90.8 \\
\hline
\end{tabular}

Table 6. Prevalence of infested animals with different species of ticks in two seasons.

\begin{tabular}{lcccc}
\hline Season & Animals examined & Number positive & Prevalence (\%) & P-value \\
\hline Dry & 173 & 135 & 78 & 0.000 \\
Wet & 173 & 158 & 91.3 & 0.001 \\
Total & 346 & 293 & 84.7 & 0.001 \\
\hline
\end{tabular}

on world market if the ticks are large in number (Solomon et al., 2001). Furthermore, more ulcers caused by this tick species become favorable sites for secondary bacterial infection like Dermatophilus congolensis (Kaufnann, 1989).

$B$. decolloratus is the second abundant tick species (26.3\%). It has been reported also as prevalent in many other parts of the country such as Riftivally (Pegram et al., 1981; Solomon and Kaaya, 1996) and in highland areas of Harer and Dire dawa district (Mannueri and Tilahun, 1991). This present finding is in agreement with tick species surveys (Gebremichael, 1993; Naser, 1985; Dessie and Getachew, 2006) in Wolaita. Similar result was also reported by Solomon et al. (2001) with similar altitude in-dicating the abundance of $B$. decoloratus in Sebeta town.

According to Bekele (2002), relative abundance of $B$. decoloratus increases from lowland towards highland. The present study disagrees with the finding of Alekaw (1998) at Metekel Ranch, Ethiopia showing a prevalence of $5.7 \%$ which may be due to the difference in geographical location and altitude factor. This tick species is abundant in wet highlands and sub highlands receiving more than $800 \mathrm{~mm}$ rainfall annually (Pegram et al., 1981). The regional distribution of $B$. decoloratus is similar to $A$. varigatum (Feseha, 1983). In this study, female Boophilus species were higher in number than males. This may be due to the fact that substantial proportion of females may be engorged in few days and fall on the ground in short period of time as compared to males. Therefore, this study was in agreement with the finding of Mekonnen et al. (2001) who also suggested that engorged females may be removed by self-grooming of the host, because of the large size. Other researchers like, Bellete (1987) and Mohammed (1977) also suggested lower number of Boophilus species in their study compared to that of female. This condition is due to the small sized of males of $B$. decoloratus makes difficult to see and get missed during collection.
A. Coherence is the third abundant tick species $(14.9 \%)$ in this present study. The prevalence of this finding was similar to other reports from South Western Ethiopia, MizanTeferi (Seid, 2004) and from Jimma (Yitbarek, 2004).

$H$. marginatum rufipes was identified as the fourth abundant tick species collected in and around Haramaya town. This tick species was collected from restricted area of the warm, moderately dry midlands with an altitude of 1800 to 1950 m.a.s.l. (Morel, 1980). Hogestral (1956) indicated that $H$. Marginatum rufipes is widely distributed in the most arid part of the tropical part of Africa which receives 250 to $650 \mathrm{~mm}$ annual rain fall and in Ethiopia it was most often collected between 1000 and 2000 m.a.s.I and rare in western high land areas. Therefore, the finding of Hogstral (1956) was in agreement with the present study. The studies of Mohammed (1985) in Wolayita Awraja and Seyoum (2001) in North Wollo zone kobo Girana valley and Solomon (1996) at Abernosa ranch are in agreement with the present finding.

$R$. evertsi being one of the least recorded tick species in the study area constituting $5.5 \%$ of the total adult tick collection. In contrast to this study, the geographical distribution survey of ticks conducted in Gonder Awraja by Eshetu (1988) found that $R$. eversti was the most common abundant tick species of the area. This may be due to geographical location, seasonal variation of the area or may be due to variation in macroclimatic factors (Singh et al., 2000) including higher rain fall associated with high soil moisture content which are favorable for the survival of tick vectors.

$R$. pulchulles was the least abundant tick species in the study area which is $5.4 \%$ in the distribution rate. This finding is in line with Solomon et al. (1998) who recorded small count. $R$. pulchellus (the zebra tick) prefers to feed on cattle, but it also infests other domestic animals (Walker et al., 2003). It was mainly collected in Eastern Tigray, Southern SNNP, Afar, Harar, Somalia and Dire Dawa, but few collections were reported from Gambella. 
The result of the present study agrees with the previous study of Surafel (1996) who reported $R$. pulchulles is as the least abundant tick species.

The present study indicates that ticks select favorable site for their attachments on the body of cattle, which is in line with the study of Fanos et al. (2012) in South Western Ethiopia and Howell et al. (1978) in South Africa who reported similar favorable site of ticks to attach themselves onto the cattle's body. The present result also revealed that the infestation of the ticks were not variable in terms of sex of the cattle, that is, male and female cattle were equally infested with ticks. There is no statistical significant difference $(p>0.05)$ between the two sexes which implies sex has no impact on the infestation rate. Both male and female animals are equally susceptible and ticks did not prefer sexes since their target is feeding of blood for their survival.

The present study also revealed that tick count was higher in the wet season than the dry season which agrees with Solomon et al. (2001) who reported that ticks were found on cattle throughout the study period, although higher loads of ticks were observed during rainy than dry period. Bekele (2002) also reported the highest total tick count during wet period than the dry period.

There is statistically significant difference $(p<0.05)$ in infestation rate among different age groups of cattle. The adults are more susceptible than calves due to the fact that the calves are not often driven with adult age groups into grazing and watering points. This practice naturally reduces the chance of exposure of calves to ticks.

The result of the present study revealed that the prevalence is getting decreased as compared to the previous studies probably due to an increase in the level of awareness of the farmers on how to reduce the tick infestation of their cattle, improvement in the management of their animals and increment of veterinarians per district. In addition to this, the climatic variation is also another factor which may contributes to decrease the prevalence of the tick infestation in the study area.

\section{CONCLUSION AND RECOMENDATIONS}

Of all ectoparasites, ticks cause the greatest economic loss in livestock production either by transmitting a wide variety of tick born diseases or by direct coursing to hides and skins. Therefore, this study on species composition and seasonal variation of tick infestation is considered primary as an aid in improving tick control in the study areas. Additionally, the study indicated that the most important and abundant species of tick infestation identified were $A$. varigatum and $B$. decolloratus. This may be due to conducive environmental factors prevailing in the areas. Therefore, the following recommendations are forwarded so as to benefit the livestock owners by overcoming the problems arising from tick infestation.

1. Strategic application of acaricides especially at the beginning of the wet months might minimize the infestation of ticks.

2. The effect of dominant tick species on the productivity of cattle and determination of the minimum load that affect productivity are warranted.

3. Encourage commonly to practice safe and economical traditional control methods as part of integrated tick management.

4. Tick should be managed at an economical acceptable level by a combination of techniques and this requires familiarity with the tick species present and an understanding of their epidemiology.

\section{Conflict of Interests}

The author(s) have not declared any conflict of interest.

\section{REFERENCES}

Alekaw S (1998). Distribution of ticks and tick-borne diseases at Metekel Ranch. Ethiop. Vet. J. 4(1):30.

Alekaw S (2000). Distribution of ticks and tick-born disease at Metekel Ranch. J. Ethiop. Vet. Assoc. 4(1):40-60.

Bekele H (2002). Studies on seasonal dynamics of ticks of Ogaden cattle and individual variation in resistance to ticks in eastern Ethiopia. J. Vet. Med. 49(6):285-288.

Bellete M (1987). A preliminary survey of ticks on four species of domestic animals in Nekemte Awraja. DVM thesis, Faculty of Veterinary Medicine.

De Castro JJ (1997). Long term studies on the economic impact of ticks on Sanga cattle in Zambia. Exp. Appl. Acarol. 21(1):3-19.

Dessie S, Getachew A (2006). Cattle tick dynamics in different agroecological zone of Walayta, Southern Ethiopia. Ethiop. Vet. J. 10(2):85-99.

Eshetu M (1998). Survey of geographic distribution of ticks in Gonder Awraja. DVM Thesis, Faculty of Veterinary Medicine, Debre Zeit, Ethiopia.

Fanos T, Gezali A, Sisay G, Bersissa k, Tariku J (2012). Identification of tick species and their preferred site on cattle's body in and around Mizan Teferi, southwestern. J. Vet. Med. Anim. Health 4(1):1-5.

Food and Agriculture Organization (FAO) (2004). Resistance management and integrated parasite control in ruminants. FAO of the United Nations. pp. 9-77.

Feseha GB (1983). Notes on tick species and tick borne diseases of domestic animals in Ethiopia. FVM, AAU, Ethiopia. pp. 1-64.

HDARDO (Haramaya District Agricultural and Rural Development Office) (2002).Socio-economic Survey report. Haramaya, Ethiopia.

Hogstral $H$ (1956). Ticks of the Sudan (with special reference to equatorial province and with preliminary review of the genera Boophilus, Margaropus and Hyalomma. pp. 5-912.

Howell CJ, Walker JB, Nevil EM (1978). Tick mites and insects infesting domestic animals in Republic of South Africa department of agricultural technical services. Science Bulletin of the Department of Agricultural Technical Services, Republic of South Africa. pp. 1-13.

Kaufnann WR (1989). Tick host interaction a synthesis of current concepts. Parapsychol. Today 5(2):47-55.

Keiser MN (1987). Ethiopia, Report on tick taxonomy and biology, FAO, Rome, Italy.

Mannueri K, Tilahun J (1991). A survey of Ectoparasites of cattle in Harer and around Dire Dama. DVM Thesis, Faculty of Veterinary Medicine, Debra Zeit, Ethiopia.

Mekonnen S, Hussein I, Bedane B (2001). The distribution of Ixodid ticks in Central Ethiopia Onderstepoort J. Vet. Res. 68(4):243-251.

Mengistu A (1997). Drought performances of F1 cross breed dairy cows and local oxen under small holder farm management conditions. Msc thesis, Haramaya University of Agriculture, Ethiopia.

Mesele A (1989). Bovine tick survey in Bahir Dar Awraja. DVM thesis, 
Faculty of Veterinary Medicine, Addis Ababa University, Ethiopia.

Gebremichael T (1993). Ticks and tick born diseases of cattle in North Omo Administrative zone. DVM thesis, Faculty of Veterinary Medicine, Addis Ababa University, Debrazeit. pp. 1-50.

Minjauw B, Mcheod A (2003). Tick-born disease and poverty. The impact of ticks and tick-borne disease on the live hood of small-scale and marginal livestock owners in India and Eastern and Southern Africa. Research Report, DFID Animal Health Programme, Center for Tropical Veterinary Medicine, University of Edinburgh, UK. pp. 1-116.

Mohammed AN (1977). Seasonal incidence of Ixodid ticks of cattle in Northern Nigeria. Bull. Anim. Health Prod. Afr. 25(3):293.

Morel P (1980). Study on Ethiopia ticks (Acarida, Ixodidae). Institut d'Elevage et de Medecine Vererinaire des Pays Topicaux, MaisonsAlfort, France. pp. 7-15.

Naser M (1989). Common tick species in Wolayta Awraja. DVM thesis, Addis Ababa University, Faculty of Veterinary Medicine, Debrezeit.

Pegram G, Hoogsstraal H, Wassef HP (1981). Ticks (Acari Ixodidea) of Ethiopia Distribution, Ecology and Host relationship of species infecting livestock. Bull. Entomol. Res. 71:339-359.

Seid B (2004). Survey of cattle tick species in and around MizanTeferi and Bench Maji zones of SNNP. DVM thesis, Addis Ababa University, Faculty of Veterinary Medicine.

Seyoum Z (2001). Study of ticks and tick born diseases on cattle of Girran Valley in the North Wollo zone. Proceedings of the Ethiopian Veterinary Association, V-15.
Solomon G, Kaaya G, Feseha G, Teferi G, Getachew T (1998). Ticks and tick born parasites associated with indigenous cattle in Dituyura Ranch, Southern Ethiopia Insect Science and its application.

Solomon G, Nigist M, Kassa B (2001). Seasonal variation of ticks on calves at Sebeta in Western Shoa zone. Ethiop. Vet. J. 7(1\&2):1730.

Singh AP, Singla LD, Singh A (2000). A study on the effects of macroclimatic factors on the seasonal population dynamics of Boophilusmicropus (Canes, 1888) infesting the cross-bred cattle of Ludhiana District. Int. J. Anim. Sci. 15(1):29-31.

Tsegaye A, Yacob H, Bersissa K (2013). Ixodid ticks infesting cattle in three agroecological zones in central Oromia: species composition, seasonal variation, and control practices. Comp. Clin. Pathol. 22(2).

Thrusfield M (1995). Veterinary Epidemiology, $2^{\text {nd }}$ ed. Blackwell Science Ltd. pp. 182-198.

Walker AR, Bouattour A, Camicas JJ, Estrada-pena A, Horak IG, Latif AA, Pegram RG, Preston PM (2003). Ticks of domestic animals in Africa: A guide to identification of species bioscience report. pp. 11221.

Yitbarek G (2004). Tick species infesting live stock in Jimma area, South west Ethiopia. DVM thesis, Faculty of Veterinary Medicine, Addis Ababa. 